\title{
La ambigüedad semántica como recurso filosófico en el Hipias Menor de Platón
}

Recibido el 03/04/2020. Aceptado el 05/06/2020.

\begin{abstract}
Resumen
El Hipias Menor es uno de los diálogos más breves de Platón. Su ubicación dentro del conjunto del corpus constituye un motivo de controversia entre los especialistas. Si bien la autenticidad del diálogo quedó probada a partir de una mención de Aristóteles en Metafísica V, 1025 a6, no han faltado quienes desestimaran absolutamente su valor filosófico. Alejados de esta postura extrema, se encuentran quienes han señalado el sentido propedéutico que tendría el diálogo respecto de algunos temas recurrentes en la obra posterior de Platón. Asimismo, en los últimos años se han propuesto lecturas que intentan mostrar las tensiones que el Hipias presentaría en relación a textos de otros socráticos. En el presente trabajo ensayaremos una vindicación del diálogo atendiendo a su valor intrínseco, considerando que Platón ofrece en él una sutil distinción de dos entramados conceptuales diferentes, sobre una misma base terminológica. Si la argumentación va por buen cauce, veremos que el gesto filosófico de Platón en este diálogo consiste en operar con una serie de términos críticos para la conciencia ateniense de finales del siglo V. a.C., para inscribir en ellos dos sentidos posibles, restituyendo de este modo la problematicidad de los mismos.
\end{abstract}

Palabras clave: Ambigüedad semántica, Hipias Menor, intelectualismo socrático, moral, voluntad

\section{Semantic ambiguity as a philosophical resource in Plato's Hippias minor}

\begin{abstract}
The Hippias minor is one of Plato's shortest dialogues. Its location within the corpus as a whole is a source of controversy among specialists. Although the authenticity of the dialogue was proven by a mention of Aristotle in Metaphysics V, 1025 a 6, there have been those who have absolutely dismissed its philosophical value. Far from this extreme position, there are those who have pointed out the propaedeutic sense that dialogue would have with respect to some recurrent themes in Plato's later work. Likewise, in recent years, readings have been proposed that attempt to show the tensions that the Hippias would present in relation to texts by other socratics. In
\end{abstract}


the present work we will try a vindication of the dialogue according to its intrinsic value, considering that Plato offers in it a subtle distinction of two different conceptual frameworks, on the same terminological basis. If the argumentation goes in the right direction, we will see that Plato's philosophical gesture in this dialogue consists of operating with a series of critical terms for the Athenian conscience at the end of the 5 th century $\mathrm{BC}$, to inscribe in them two possible meanings, thus restoring their problematic nature.

Keywords: Hippias minor, Semantic ambiguity, Socratic intellectualism, Morality, Will

\section{Introducción: problemas de interpretación}

Dos tesis determinan la organización del Hipias Menor. La primera se encuentra en la mitad del texto (369b), y sostiene que es el mismo hombre (ho autòs) el falaz y el veraz (pseudès te kaíalethès). La segunda, enunciada de forma condicional, aparece en la última página del texto y dice: "el que yerra voluntariamente (hekòn) y hace cosas vergonzosas e injustas (ádika), si es que este existe, Hipias, no podría ser otro que el hombre bueno (ho agathós)" (376b 6-7). ${ }^{1}$ Frente a estas dos partes del diálogo la bibliografía especializada ha planteado distintos problemas agrupables en tres ejes centrales: 1) cuestiones de método, 2) validez de la argumentación, 3) sentido de la tesis según la cual el que yerra voluntariamente, si es que existe, es el bueno.

Alrededor del primer eje se concentran, por un lado, los estudios que intentan determinar el modo en que el diálogo permite observar el método de refutación socrático, su proceder dialéctico, así como también la valoración platónica de otras prácticas vinculadas al conocimiento en el momento en que escribió el Hipias Menor, como es el caso de la crítica literaria (cfr. Vlastos, 1998: 366; García Baró, 2000:39-54; Mársico, 2011: 47-81; Reale, 2015: 49-71). Por otro lado, en correspondencia con estas cuestiones, todavía dentro del primer eje, se ha planteado la duda respecto de con quién está polemizando Platón en este diálogo, ya que, si bien es evidente que Hipias aparece aquí como el interlocutor directo, se han encontrado puntos de contacto entre este texto y uno de los testimonios de Porfirio sobre Antístenes, lo cual ha hecho sugerir la posibilidad de que estén en juego argumentos dirigidos a polemizar con el socrático (cfr. Brancacci, 1990: 64-69; Blundell, 1992: 144, Lampert, 2002; Mársico, 2011; Venturelli, 2017).

Dentro del segundo eje debemos ubicar los trabajos dirigidos a mostrar las falacias que habría en el curso de la primera y la segunda argumentación. El grueso de comentadores que siguen esta línea señala la ambigüedad con que Platón habría usado ciertos términos como agathós, polýtropos, áristos, y habría efectuado pasos inválidos en los razonamientos como consecuencia de la equivocidad de los significados (cfr. Guthrie, 1965: 192). Sin embargo, otros autores sostienen que la valoración meramente formal de la construcción argumentativa del Hipias perdería de vista el modo irónico con el que Sócrates enfrenta la pedantería del sofista (cfr. Reale, 2015: 49).

El tercer eje es, sin duda, el más crucial. En efecto, la suerte que corre el conjunto del diálogo en cuanto a su relevancia dentro del corpus depende de cómo se interprete la paradoja final. La cuestión que se plantea es en qué medida la afirmación según la cual el que yerra voluntariamente es, si es que existe, el mismo que el justo, choca contra alguna de las formas en que se presenta el llamado intelectualismo socrático, cuando no contra cualquier otra teoría moral. Así, las aguas se dividen entre, por 
un lado, quienes consideran que la paradoja mostraría la contradicción a la que se llega cuando se toma la relación de un saber con la verdad desde un punto de vista meramente técnico, por fuera de cualquier consideración ética (cfr. Araujo, 2005; Mársico, 2011: 72, Fronterotta, 2017: 88), y, por otro lado, quienes consideran que se trataría de una falsedad moral, ante cuya evidencia solo queda el desconcierto (cfr. Kahn, 2011: 134). Como es evidente, la interpretación de este pasaje condiciona significativamente la decisión que se tome respecto de las cuestiones planteadas en los primeros dos ejes, bien porque al declarar la incoherencia de la paradoja se desestime así la importancia del diálogo en su totalidad, o bien porque al afirmar la coherencia de la paradoja se ilumine el sentido de la metodología socrática y los giros de la argumentación.

\section{Observación metodológica e hipótesis del trabajo}

Las estrategias hermenéuticas utilizadas para resolver esta cuestión, cualquiera sea la conclusión que se pretenda, no han tenido suficientemente en cuenta que los términos utilizados en la paradoja no reportan una semántica fija y ahistórica. ${ }^{2}$ En efecto, el problema se plantea sobre la idea de que la conjunción de los conceptos de injusticia (adikia) y acto voluntario (hekón) conduce a la contradicción que señalábamos hace un momento en el ámbito moral, y se supone así que efectivamente Platón tiene en mente la misma idea de voluntariedad que desarrollaría en diálogos posteriores, si es que, por otro lado, puede hablarse de una única e inequívoca concepción platónica de voluntad (cfr. Bieda, 2020: 8-14). Esta perspectiva pierde de vista una cuestión central, a saber, que en un contexto histórico sentido como crítico respecto de la relación entre lenguaje y ontología la filosofía del joven Platón buscaba, precisamente, la reconstitución de la potencia de los discursos para dar cuenta de lo real (cfr. Livov y Spangenberg, 2012: 21), y no todavía la construcción de un sistema a partir de términos cuyo significado ya estuviera claramente determinado. Los contados casos en que la bibliografía secundaria ha observado la importancia de la semántica de hekón en el contexto de la conversación que mantienen Sócrates e Hipias han sido para señalar la ambigüedad en la que descansarían los pasos inválidos de la argumentación sostenida por Platón (cfr. Mulhern, 1968: 283). Se trata de señalamientos, en general vinculados a plumas anglosajonas, que buscan el descrédito del razonamiento bajo la premisa de que toda ambivalencia semántica es un defecto, desestimando completamente la posibilidad de que, por el contrario, en el contexto de producción de este texto, la utilización bivalente de un término constituya un recurso filosófico destinado a rescatar, por ejemplo, la voz "hekón" de su aspecto meramente fónico. De hecho, si nuestra argumentación va por buen cauce, veremos que el verdadero gesto positivo de Platón en este diálogo consiste en operar con una serie de términos críticos para la conciencia ateniense de finales de siglo $\mathrm{V}$ a.C. para luego distinguir, o si se quiere, inscribir en ellos dos sentidos posibles, de manera tal que se restituya la problematicidad de los mismos. En este sentido, la paradoja que cierra el diálogo vendría a expresar, según intentaremos sostener, un dato filosófico positivo que construye un problema teórico en un contexto histórico marcado por la indeterminación de criterios científicos y morales, en el que, como cuenta el propio Platón en la Carta VII, "todo iba a la deriva por todas partes" (325 d 1). Así, el valor del Hipias Menor no sería meramente propedéutico, porque no se trata, según veremos, de la preparación de un terreno, sino más precisamente de la invención misma del terreno sobre el que más adelante se resolverán discusiones decisivas.

2 Con ocasión de fundamentar la idea de un abordaje filosófico en el estudio de la lengua griega, Bieda (2018: 40) arguye que todo texto ofrece "zonas semánticamente dinámicas", frente a las cuales la pericia técnica -referida a la materialidad de la lengua- no alcanza, sino que se requiere una disposición hermenéutica abierta, creativa, en suma, filosófica, que impida la clausura definitiva del sentido. Tomando prestada la terminología de Bieda, podríamos afirmar que el pasaje que nos ocupa representa una de esas "zonas semánticamente dinámicas". 


\section{Ambigüedad: lenguaje y ontología}

“¿Y tú por qué estás callado?" (363a 1). El joven Platón decidió que el Hipias Menor comenzara con esa pregunta, con la pregunta acerca del porqué del silencio de Sócrates en un contexto de reunión, luego de que Hipias acabara de ofrecer un discurso epidíctico sobre temas homéricos. Cabe pensar que esta primera línea ya prefigura el tópico de la reñida relación entre palabra y realidad. El personaje Éudico es el que hace la pregunta esperando que Sócrates manifieste estar de acuerdo (synepaineîs) o se disponga a refutar (elénxeis) las cosas dichas por Hipias. Sócrates accede a intervenir, pero para llevar los hilos de la conversación hacia problemas que trascenderán la temática homérica, cumpliendo de esta manera con un recorrido que nace en el silencio para terminar en la estruendosa postulación de una tesis contradictoria. En lo que sigue acompañaremos esta peripecia socrática para intentar registrar los significados que a lo largo del diálogo se van adosando a los términos en juego en la paradoja final.

\section{II.1. "Dejemos tranquilo a Homero"}

La primera cuestión que plantea Sócrates es la de decidir qué héroe fue mejor, si Odiseo o Aquiles (363b-c). Hipias, luego de autoproclamarse sabio en todas las materias, responde lo siguiente:

Digo que Homero ha compuesto, por un lado, a Aquiles como el mejor (áriston) de los que llegaron a Troya, por otro lado, a Néstor como el más sabio (sophótaton), y por otro, a Odiseo como el más polifacético (polytropótaton) (364c 5-8).

Sócrates, a su vez, dice comprender la caracterización de los primeros dos héroes, pero pide una aclaración respecto del significado de la polytropía de Odiseo. De esta manera, Platón introduce en el diálogo un tópico de discusión habitual entre sus contemporáneos. ${ }^{3}$ Sin embargo, en este caso el tema de la polytropía no es sino un tema de paso hacia otro problema mayor. Luego de que Sócrates pidiera claridad respecto de la caracterización de Odiseo, Hipias deja establecido que cuando habla de alguien polýtropos habla de alguien falaz (pseudés). De este modo, el diálogo sobrevolará el tópico homérico para pasar a destacar la cuestión específica del lenguaje desde el punto de vista de la posibilidad del ejercicio de la mentira. Leemos (365 d 1-5):

Sócrates: Dejemos tranquilo a Homero, porque no es posible volver a preguntarle pensando en qué compuso estas palabras. Pero tú, ya que adoptas abiertamente su causa, contesta a la vez por Homero y por ti.

Hipias: Que así sea. Pregunta puntualmente lo que quieras.

\section{2. Introducción del concepto de dýnamis}

La cuestión que plantea Sócrates es la siguiente e (365d5-6):

¿Dices que los falaces son incapaces (adynátous) de hacer algo, como los enfermos, o son capaces de hacer algo?

Considerada de cerca, la pregunta encierra una definición de dýnamis que es, en principio, negativa, porque significa lo contrario a la incapacidad de los enfermos, y

\footnotetext{
3 De hecho, contamos con un fragmento de Antístenes legado por Porfirio en el que el socrático se dedica exclusivamente a dilucidar el significado de la polytropía de Odiseo. Como señala Brancacci (1990: 45), este texto representa un ejemplo de la aplicación del método de investigación de los nombres

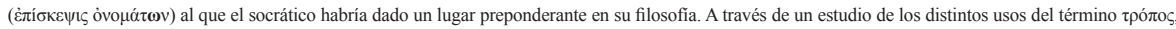
Antístenes argumenta en contra de la valoración moral negativa de Odiseo, para defender, en cambio, que quien tiene muchos tрómoi a la hora de hablar, lejos de ser un farsante o un mentiroso, es un бoфóç, un sabio. Para un análisis comparativo de este fragmento con el Hipias Menor cfr. Lampert (2002), Mársico (2005), y Venturelli (2015)
} 
general, porque se trata de una capacidad de "hacer algo" (tipoîin) y no de hacer tal o cual cosa en particular. Asimismo, un poco más adelante Sócrates volverá a referirse a este concepto, pero aclarando más sobre su significado (366c 1-5):

Sócrates: Es capaz cada uno que haga lo que quisiere cuando quisiere (hós àn poiê tóte hó àn boúletai, hótan boúletai). No me refiero a los que están impedidos por enfermedad ni asuntos por el estilo, sino como tú eres capaz de escribir mi nombre cuando quieras. A eso me refiero. ¿O no llamas capaz al que es así?

Como puede observarse, se trata de una noción de dýnamis que supone la inexistencia de condicionamientos externos, motivo que nos habilita a avanzar un paso más en el análisis que proponemos, ya que no solo se trata de una concepción a la que se llega negativamente y de modo general, sino también suponiendo esta premisa liberal, en un sentido laxo de la palabra. Por otro lado, si agudizáramos nuestra atención sobre la explicatio de Sócrates ("a esto me refiero"), podríamos señalar que no necesariamente la capacidad de hacer algo en términos generales coincide con la capacidad particular de escribir, ya que la incapacidad de escribir no tiene que ver con una enfermedad, sino con la falta de un saber adquirible. Ésta es exactamente la distinción que realiza Aristóteles en De Anima II, 5, con ocasión de mostrar las distintas capas en las que debe estudiarse la facultad sensitiva (tò aisthetikón). Como sea, Hipias acepta sin reparos la epexégesis de Sócrates y la conversación sigue adelante, quedando en pie una primera noción dýnamis.

\section{3. Sophía neutral como condición formal de la dýnamis}

Ahora bien, ¿qué condición positiva debe cumplir el pseudés para efectivamente poder mentir más allá de contar con una dýnamis en sentido liberal? La respuesta aparece rápidamente en el diálogo: el pseudés debe ser sophós con respecto a aquello sobre lo cual pretende mentir. En efecto, el pseudés, dado que es sagaz, sabe lo que hace porlo menos cuando engaña. La conclusión a la que se arriba es que, en definitiva, los falaces son los capaces y sabios para mentir ( 366 b 5). ${ }^{5}$ De esta manera, Platón establece la condición de posibilidad de la elección de dar al discurso un contenido falso. Y esta condición, insistamos, es el saber sobre lo que se habla.

Ahora bien, ¿qué clase de saber es este? Desde el comienzo del diálogo, Platón hace de Hipias el paradigma de esta particular sapiencia (364 a 1-5).

Sócrates: Te pasa algo grandioso, Hipias, si en cada Olimpíada llegas al templo con ánimo tan seguro en tu alma en relación con la sabiduría. (...)

Hipias: Naturalmente, Sócrates, me pasa eso, porque desde que empecé a competir en Olimpia nunca encontré a nadie mejor que yo en nada.

Lo que sigue a este pasaje es la comprobación de que, efectivamente, el sofista es capaz de hablar con veracidad y con falsedad en todas aquellas áreas de conocimiento que domina. En asuntos de cálculo es capaz de ser falaz a la hora de responder de manera deliberadamente errónea, por ejemplo, cuánto es setecientos por tres (367ad), lo mismo muestra en el caso de la geometría (367e), y en el caso de la astronomía (368a). Sin embargo, este tipo de saber no sirve para decidir si está bien o si está mal

4 Vale aclarar: decimos "liberal" en el sentido de que el fundamento de la dýnamis reside en el individuo mismo sin afectación de las variables contextuales, o, dicho de otro modo, el agente es libre en lo que a su entorno externo respecta. El eco de esta concepción resuena en un pasaje de República VIII. Desdeñosamente dice Sócrates, describiendo la organización democrática: “¿No sucede que son primeramente libres los ciudadanos, y que en el Estado abunda la libertad, particularmente la libertad de palabra y la libertad de hacer en el Estado lo que a cada uno le da la gana?" (Rep. 557 b 4-5; trad. C. Eggers Lan). $5 \mathrm{Si}$ bien excede el propósito de nuestro trabajo, debemos señalar que el problema de la mentira es retomado en República II 382 b-d desde otra perspectiva. Allí, Platón establece una distinción entre una falsedad alojada "en el alma" (en tê psykhêe), y otra "en las palabras" (en toîs lógois). Para un tratamiento detenido de la conexión entre el Hipias Menor y República sobre este punto Cf. Macías y Marcos (2012) 
mentir o decir la verdad, sino que explica la diferencia entre poder o no poder decidir la dirección del discurso. Solo quien sabe sobre qué habla puede actualizar la dýnamis de orientar su lógos (cfr. Casertano 2007: 33; Araujo, 2005/6: 161). De hecho, en este sentido Sócrates concluye que el capaz de ser falaz es también el más capaz de ser veraz, pues el que tiene el saber de aquello sobre lo que habla es el mismo (autós) que puede hacer corresponder o no su discurso con la realidad ( $369 \mathrm{~b} 2$ ). Se trata, en definitiva, de una concepción del saber neutral desde el punto de vista moral, concepción estrechamente vinculada a la idea liberal de la capacidad deliberativa, precisamente porque no implica ninguna restricción más que la estrictamente formal. ${ }^{7}$ De esta manera, queda presentada una primera respuesta a la pregunta por las condiciones de la práctica efectiva de la mentira vinculada a un tipo de saber que garantiza el ejercicio liberal de decidir en cada caso lo que se quiera decir.

\section{4. Inclusión de la dimensión moral}

\section{a) Ocurrencia del concepto de adikía como parámetro de comparación}

Si el veraz y el falaz son, desde este punto de vista, el mismo y no son distintos, entonces Aquiles y Odiseo no difieren esencialmente en cuanto a su modo de ser, como sostenía Hipias en el comienzo de su presentación. Es forzoso admitir - dice Sócrates-que "si Odiseo era falaz, también resulta veraz, y si Aquiles era veraz, también resulta falaz" (369b 4-5). Frente a este corolario, el sofista intenta introducir una variable moral para defender la preeminencia de Aquiles, arguyendo que este héroe, si miente, lo hace involuntariamente (ákon), mientras que Odiseo, cuando miente, miente deliberadamente (hekón $n$ ), pero Sócrates, jugando todavía con la dimensión formal de los términos en juego, responde que, si ese fuera el caso, entonces con más razón Odiseo sería mejor (ameínon), ya que el que miente voluntariamente es mejor que el que miente involuntariamente. Hipias no comprende la distinción con la que está operando Sócrates en el plano formal, e incluye por primera vez en el diálogo la noción de adikía o injusticia, desplazando definitivamente el problema de la voluntariedad de las acciones al plano moral (372a 1-5):

¿Y cómo, Sócrates, los que cometen injusticia voluntariamente y traicionan y hacen cosas malas voluntariamente podrían ser mejores que los que actúan involuntariamente, que merecen una amplia disculpa, si es que se comete injusticia o se miente o se hace algún otro mal sin saberlo?

\section{b) Establecimiento de la oposición entre sophía neutral (concepción "liberal”) y sophía con incidencia positiva sobre la dýnamis de actuar hekón (concep- ción "moral-determinante")}

El sofista no ha advertido el nivel de análisis en el que se movía Sócrates y ha mezclado la dimensión formal con una inquietud moral. Sin embargo, Sócrates aprovechará la ocasión para poner en tensión la concepción de voluntariedad que se viene suponiendo - asociada al hacer lo que se quiera cuando se quiera - con otra concepción opuesta, recuperando de este modo, no ya uno, sino dos significados posibles para el mismo concepto (372 e 1- 6):

Ahora, en este momento, me ha venido como una enfermedad y me parece que los que yerran voluntariamente sobre algo (hoi hekóntes examartánontes perí ti) son mejores que los que [yerran] involuntariamente (beltíous einai tôn akótonn).

\footnotetext{
6 En esta línea, Mársico (2011: 72) sostiene que "el planteo íntegro resulta ser una crítica sobre la neutralidad de las técnicas, que en épocas de Platón acusaban ya un sostenido proceso de instauración disciplinar”. También Fronterotta (2014: 88): “( ...) si se sostiene que el conocimiento es moralmente neutro, en la medida en que sus 'modos de uso' pueden variar conforme al sujeto que los practica, este conocimiento no podrá identificarse jamás con la excelencia moral" (trad. mía).

7 Es decir, impide al agente afirmar con pretensión de verdad que $2+2$ es igual a 9.
} 
Pero afirmo que la culpa (aitious) de la enfermedad (pathématos) presente es de los argumentos anteriores (toùs émprosthen lógous), de manera que en este momento me parece que los que hacen cada una de estas cosas de manera involuntaria son peores que los que las hacen voluntariamente.

Bajo una primera lectura, observamos una tesis bien clara, a saber: los que yerran voluntariamente (hekón) son mejores que los que yerran involuntariamente. Esta idea se relaciona con la concepción liberal de las elecciones del agente. En este sentido, Sócrates es transparente y quiso decir lo que dijo: es mejor ser capaz que ser incapaz, porque si se es capaz significa que se tiene un conocimiento sobre aquello a lo que se aplica la capacidad, y tener ese conocimiento es mejor que no tenerlo. Sin embargo, al mismo tiempo, en el modo en que plantea la tesis podemos ver que se sugiere otro concepto de "voluntad" y otro concepto de saber. Sócrates sostiene la tesis de que son mejores los que yerran voluntariamente, pero lo hace, según sus propias palabras, movido involuntariamente por una repentina enfermedad, y esta enfermedad (páthéma), a su vez, es rápidamente identificada con los argumentos anteriores (toùs émprosthen lógous). Se trata, en suma, de otro tipo de involuntariedad, distinta a la de la mera incapacidad, relacionada ahora con un particular sentimiento de imposición por parte de la razón o lógos sobre la dirección del querer. "Involuntariedad" decimos, acompañando la ironía deliberada de Sócrates, porque, bajo la concepción que hemos llamado liberal, la determinación de la dirección de la voluntad desde una necesidad ajena al querer del agente es concebida como una restricción y no como un ejercicio de "libertad". Sin embargo, lo que desde esta perspectiva es tomado como una restricción, desde la lógica que empezará a delinear Platón y que alcanzará sus rasgos definitivos en los diálogos medios se trata de una determinación que, por el contrario, rescata al agente de la arbitrariedad de sus pasiones (cfr. Menón, 77 b, Protágoras, 358 c, Gorgias 468c.). Se trata de un tipo de conocimiento que impone al agente la necesidad de comulgar con la verdad a la que racionalmente ha arribado. Sócrates dice que no puede evitar concluir lo que le mandaban los lógoi sobre los que se venía articulando la conversación. De este modo, quedan establecidos dos constructos conceptuales diferentes, basados en dos concepciones del saber opuestas y contradictorias. Por un lado, una concepción del saber neutral desde el punto de vista moral, y, por otro lado, una concepción del saber que podemos llamar moral- determinante, que supone la incidencia necesaria del lógos sobre el querer del agente.

\section{5. Planteo del problema de la fundamentación moral del conocimiento}

Si bien se ha sugerido en el pasaje anterior una relación de implicancia necesaria entre saber y veracidad, gracias a la cual ya no habría lugar para dirigir el discurso hacia la mentira deliberadamente, todavía, sin embargo, no se ha identificado la verdad con el bien. Esto quiere decir, en otras palabras, que en este punto del diálogo comienza a gravitar el problema de la fundamentación moral última de este tipo del conocimiento, o, dicho con otras palabras, aparece la pregunta de por qué es moralmente mejor decir la verdad que mentir. La cuestión que se abre, en suma, luego de la postulación esquemática de la nueva concepción del conocimiento es la pregunta por la justicia, por su naturaleza y por su relación con la verdad. Precisamente sobre este punto recaerá lo que resta del diálogo: sobre una definición provisoria de justicia a partir de la cual será posible observar las implicancias morales de las dos concepciones de voluntariedad y conocimiento que se han puesto en tensión. 
Sócrates: ¿La justicia no es una capacidad, o un conocimiento, o ambas cosas? ¿O no es necesario que la justicia sea una de estas cosas?

Hipias: Sí. (374 d 8 - 375 e 1)

Si las opciones ofrecidas por Sócrates son exhaustivas es porque se presupone que la justicia es una actividad del alma y no del cuerpo, y las propiedades del alma se reducen en este diálogo a la capacidad (dýnamis) y a la sabiduría (cfr. Reale, 2015: 58-59). En lo que sigue se examinan todas las posibilidades ( 375 d 8-375 e 10):

Sócrates: ¿Entonces, si la justicia es una capacidad (dýnamis) del alma, el alma más capaz es la más justa?

Hipias: Así nos parecía.

Sócrates: ¿Y qué pasa si es un conocimiento (epistémene? ¿El alma más sabia no resulta la más justa, mientras que la más ignorante será la más injusta?

Hipias: Sí.

Sócrates: ¿Y qué pasa si es ambas cosas? ¿La que tiene ambas cosas, conocimiento y capacidad, no será la más justa, mientras que la más ignorante será la menos justa? ¿No es necesario que sea así?

Hipias: Parece.

Sobre la base de esta caracterización de la justicia, Hipias tendrá que admitir que, dado que en todo caso siempre es mejor saber, y, además, que realizar una acción injusta voluntariamente supone el conocimiento de la justicia, entonces el que realiza una acción injusta de manera voluntaria es mejor que aquel que realiza una acción injusta de manera involuntaria. Sócrates enuncia esta conclusión en la famosa paradoja final, pero lo hace introduciendo una prótasis condicional que resulta central para la comprensión total del diálogo (376b 7-7):

Sócrates: el que yerra voluntariamente y hace cosas vergonzosas e injustas, si es que existe (eíper tís estin hoûtos), no podría ser otro que el hombre bueno.

Preguntémonos, entonces: ¿es posible que exista alguien tal que teniendo la epistéme de la justicia ejerza, sin embargo, la injusticia deliberadamente? Desde el punto de vista del entramado conceptual constituido por el par conocimiento neutraly voluntad liberal la respuesta es que sí, que es posible, ya que dicho conocimiento no es más que una condición formal de la capacidad del agente para decidir la orientación de su acción. En cambio, desde el punto de vista introducido irónicamente por Sócrates, según el cual el conocimiento impone necesariamente la dirección de la voluntad del agente hacia la verdad -concepción "moral-determinante"-, la respuesta es que no, que no es posible que exista alguien así, porque siendo la justicia materia de conocimiento epistémico, una vez alcanzada, el agente no puede sino ser consecuente con ella.

Con estas dos posibles resoluciones de la tensión abierta en el condicional se completan dos esquemas conceptuales diferentes y contrapuestos entre sí. Ciertamente, los signos de una posible teoría que supere la ambigüedad estructural del diálogo están presentes en el modo en que Sócrates se inclina permanentemente a mostrar las insuficiencias e inconsistencias de las concepciones del sofista. Sin embargo, aun así, no hay nada parecido a una tesis definitiva respecto de la relación entre acciones hekón, sophía, epistéme, y dikaiosýne, porque para ello, para una teoría conclusiva, se necesitaría una justificación de la aquí todavía provisoria definición de justicia como ciencia, justificación que constituirá el tópico central de la doctrina platónica desde el Protágoras a República. El Hipias Menor cumple con la construcción positiva de un problema de determinaciones contradictorias que establece una agenda para la reflexión filosófica venidera. En la última página del diálogo, luego de que Hipias diga que no puede aceptar la paradójica conclusión a la que se ha llegado, Sócrates vuelve 
a mostrar irónicamente la senda conceptual por la que debe abordarse el problema (376c1): “(...) es necesario (ávaүkaîov) que así nos parezca ahora según el lógos”.

\section{Conclusiones}

En este trabajo hemos querido mostrar el modo en que Platón operó sobre ciertos términos clave, en particular sobre la tríada "poder" "saber", y "querer", distinguiendo en ellos una semántica doble, correspondiente a cada uno de los dos entramados conceptuales establecidos: por un lado, el entramado constituido por una concepción neutral-liberal, y, por el otro lado, el esquema explicativo que llamamos "moral-determinante". En este sentido, consideramos que el diálogo en su totalidad constituye una pieza filosófica positiva, en la medida en que, no solo plantea una aporía, sino que, al mismo tiempo, construye el marco teórico para su resolución. Los intérpretes que ven en el Hipias una obra anticipatoria de problemas posteriores tienen, en efecto, razones sólidas. Sin embargo, según nuestra lectura, no se hace suficiente justicia al valor intrínseco del diálogo si no se repara en el hecho de que, en el contexto en el que emergió, el Hipias representa un paso filosófico decisivo, en la medida en que ofrece, a través de un juego deliberado de ambigüedades, la primera formulación doctrinaria del problema de la relación del agente con sus acciones. 


\section{Bibliografía}

\section{Fuentes primarias: ediciones y traducciones}

" Burnet, I. (1963). Platonis Opera. Recognovit brevique adnotatione critica instruxit loannes Burnet, I-V, Oxford.

"Mársico, C. (2011). Hipias Mayor, Hipias Menor (con introducción y notas). Buenos Aires: Losada

" Mársico, C. (2011). Filósofos Socráticos, Testimonios y Fragmentos II, Antistenes, Fedón, Esquines y Simon (con introducción y notas). Buenos Aires: Losada.

» Reale, G (2015). Ippia Minore, sul falso, (trad. saggio introduttivo, e note). Milano: Bompiano

» Zaragoza y Gómez Cardó (2007). Platón. Carta VII. (Traducción). Madrid: Gredos.

\section{Bibliografía secundaria}

» Araujo, C. (2006). O poder do falso no Hípias Menor de Platâo, Kléos, n9/10, 145162.

» Bieda, E. (2018). Griego Filosófico. Buenos Aires: Teseo.

»Bieda, E. (2020). Patón y la voluntad, Buenos Aires: Miño y Dávila

"Brancacci, A. (1990). Oikeios Logos la Filosofia Del Linguaggio di Antistene: Napoli.

» Blundell, W.B. (1992). Character and meaning in Plato's Hippias Minor, Oxford Studies in Ancient Philosophy, 131-172

»Casertano, G. (2007). Paradigmi della veritá en Platone. Roma: Editori Riuniti

»Fronterotta, F. (2017). Virtude, engano e conhecimento no Hípias Menor de Platão, Revista Archai, 12, 85.

" García Baró, M. (2000). Hippias Menor o el hombre que se diría que es malo por su bondad, Daimon, Revista de Filosofía, 21, 39-54.

"Guthrie, W. (1965). Historia de la filosofía griega IV, Gredos: Madrid.

» Kahn, C. (2011). Platón y el diálogo socrático. El uso filosófico de una forma literaria. Madrid: Escolar y Mayo.

" Lampert, L. (2002). Socrates' Defense of Polytropic Odysseus: Lying and WrongDoing in Plato's 'Lesser Hippias', The Review of Politics, 64 (2), 231-259

» Livov, G. \& Spangenberg, P. (eds.). (2012). La palabra y la ciudad. Retórica y política en la Grecia Antigua. Buenos Aires: La bestia equilátera

» Macías, J. \& Marcos, G. E. (2012). El tratamiento de la 'noble mentira' en República", Livov, G. \& Spangenberg, P. (eds.), La palabra y la ciudad. Retórica y política en la Grecia Antigua (285-309). Buenos Aires: La bestia equilátera.

» Mulhern, J. (1968). Trópos and polytropía in Plato's Hippias Minor, in Phoenix 22.4, Ontario, 283-8 
"Venturelli, S. (2015). L'Ippia Minori di Platone e il suo rapporto con Antistene (S.S.R. V A 187), Studi Classici e Orientali 61(1), 77-96

»Vlastos, G. (1998). Socrate, il filosofo dell'ironia complessa (trad. Andrea Blansina). La Nuova Italia: Firenze. 
